\title{
INDIOS PURIS E GOITACAZES: ANÁLISE SOBRE A PRESENÇA INDÍGENA NA SERRA DA MANTIQUEIRA E VALE DO PARAÍBA
}

\author{
Maurício de Souza Lino ${ }^{1}$ \\ Claudia Elena dos Santos Silva² \\ Katerine Roman Barreto ${ }^{3}$
}

Resumo: Esse texto tem como objetivo analisar a presença dos índios Puris e Goitacazes na região do Vale do Paraíba e da Serra da Mantiqueira do século XVII ao XVIII, partindo da corrida do ouro. Analisa um recorte bibliográfico especifico proveniente da historiografia, antropologia e relatos de viajantes que registram a passagem de grupos indígenas percorrendo a região. Busca-se identificar e investigar sobre a presença destes grupos no Vale do Paraíba e Serra da Mantiqueira. Procura evidenciar aspectos de sua cultura, bem como a análise dos nomes atuais de algumas localidades. Para responder ao questionamento de como surgiu essa presença indígena na região, a presente pesquisa parte da hipótese de que a evidência está associada ao desbravamento e exploração da região pelos exploradores e bandeirantes do Brasil e exterior.

Palavras-chave: Índios; Goitacazes; Puris; Serra da Mantiqueira; Vale do Paraíba.

\footnotetext{
${ }^{1}$ História/Universidade do Vale do Paraíba, Brasil. E-mail: mauriciodesouzalino@outlook.com.

2 História/Universidade do Vale do Paraíba, Brasil. E-mail: claudiaedossantos@outlook.com.

${ }^{3}$ História/Universidade do Vale do Paraíba, Brasil. E-mail: katerineroman@yahoo.com.br.
} 